\title{
EFEITO DA ADUBAÇÃO COM FÓSFORO DO CAPIM MOMBAÇA EM SOLOS COM TEXTURAS ARENOSA E ARGILOSA
}

\author{
AGRONOMICAL CHARACTERISTICS OF THE MOMBAÇA GRASS FERTILIZED WITH \\ PHOSPHORUS IN SANDY AND LOAMY SOILS
}

Oliveira, P.S.R. ${ }^{1 *}$, Deminicis, B.B. ${ }^{2}$, Castagnara, D.D. ${ }^{1 A}$ e Gomes, F.C.N. ${ }^{3}$

${ }^{1}$ Centro de Ciências Agrárias. Universidade Estadual do Oeste do Paraná-Unioeste. Marechal Cândido Rondon, PR. Brasil. *rabelo.oliveira@hotmail.com; Adeisecastagnara@yahoo.com.br ${ }^{2}$ Centro de Ciências Agrárias. Departamento de Zootecnia. Universidade Federal do Espírito Santo-UFES. Alegre, ES. Brasil. brunodeminicis@hotmail.com

${ }^{3}$ UNIMAR-Universidade de Marília. Marília, SP. Brasil.

\section{PALAVRAS CHAVE ADICIONAIS}

Matéria seca. Panicum. Parte aérea. Perfilhos.

\section{RESUMO}

O objetivo foi avaliar, em dois cortes, o efeito de doses de fósforo sob o perfilhamento, a produção de massa seca da parte aérea, de folhas, de colmos e de raízes de capim Panicum maximum 'Mombaça' cultivado em vasos foi conduzido em ambiente protegido na Fazenda Experimental Marcello Mesquita Serva, da UNIMAR, em Marília-SP, num delineamento experimental inteiramente casualizado, em esquema fatorial $4 \times 2$, com três repetições: quatro doses de $P(0,300,600$ e $900 \mathrm{mg} / \mathrm{kg}$ de solo), na forma de superfosfato triplo e dois tipos de solos: Latossolo Vermelho Amarelo Eutrófico e Argissolo Vermelho Amarelo Eutrófico. Houve interação significativa para número de perfilhos, que aumentaram de forma linear com as doses de fósforo. Em ambos os cortes, a partir de $300 \mathrm{mg}$ $\mathrm{P} / \mathrm{kg}$ de solo, associado à maior massa seca de colmos obteve-se maior massa seca da parte aérea. Considerando a produção de massa seca da parte aérea a dose tecnicamente mais apropriada foi a de $300 \mathrm{mg} \mathrm{P} / \mathrm{kg}$ de solo.

\section{SUMMARY}

This study was conducted to evaluate, in two cuts, the effects of Phosphorus rates on tillering, dry matter production of leaves and stems, and the aerial dry matter production of Panicum maximum 'Mombaça' cultivated in jars with Eutrophic Red

\section{Additional KEYWORDS}

Dry matter. Panicum. Aerial part. Tillers.

Yellow Latosol and red-yellow argisoil. The experiment was led under controlled environment in Experimental farm Marcello Mesquita Serva, of UNIMAR, in Marília-SP, Brazil. A factorial design 4 $x 2$, completely randomized with three repetitions was used. The treatments were four doses of $P$ as triple superphosphate $(0,300,600$ and $900 \mathrm{mg}$ $\mathrm{P} \mathrm{kg}^{-1}$ of ground). There was significant interaction with the tiller number. Considering the dry matter aerial production the most technical appropriate dose was $300 \mathrm{mg} \mathrm{P} / \mathrm{kg}$ of ground.

\section{INTRODUÇÃO}

A pecuária brasileira é sustentada em pastagens, pela sua praticidade e economia, porém, os resultados econômicos obtidos pela maioria dos pecuaristas estão muito abaixo das possibilidades produtivas (Vitor et al., 2009). Um dos motivos relacionados ao déficit produtivo da pecuária é a baixa fertilidade dos solos brasileiros (Santos $e t$ al., 2002), sendo os níveis extremamente baixos de fósforo (P) disponível e total e a alta capacidade de adsorção desse elemento, um dos maiores problemas no estabelecimento e na manutenção de pastagens (Cecato et al., 2004).

$\mathrm{O}$ crescimento de uma planta não é 


\section{OLIVEIRA, DEMINICIS, CASTAGNARAE GOMES}

dependente de um único elemento, mas do nível de cada nutriente essencial (Fonseca et al., 2000). Entretanto, o P está entre os elementos mais importantes para o vigor e desenvolvimento das plantas (Cecatto et $a l .$, 2007). Na implantação das pastagens o $\mathrm{P}$ contribui para a formação do sistema radicular, devido à sua absorção ser limitada pela baixa mobilidade no solo e reduzido sistema radicular inicial das plantas (Santos et al., 2002), enquanto na fase de manutenção, favorece o desenvolvimento da parte aérea e das raízes (Belarmino et al., 2003). Essas características fazem com que a adubação fosfatada assuma papel fundamental para o estabelecimento e a manutenção das pastagens (Cecatto et al., 2007).

Os Latossolos de textura média e argilosa necessitam quantidades muito mais elevadas que as exigidas pela planta, pois parte do P aplicado pode ser adsorvido e, ou, precipitado em formas menos solúveis, tornando-se momentaneamente indisponível às plantas (Mesquita et al., 2004). Para solos arenosos sabe-se que os são considerados muito frágeis ou marginais em relação à sua utilização agrícola, e o uso intensivo desses solos, portanto, é restrito, principalmente pela baixa capacidade de armazenamento de água e alta suscetibilidade à erosão, dentre outros aspectos (Oliveira et al., 2003). Os níveis de $\mathrm{P}$ também são muito baixos a baixos, pois o nutriente solúvel em água fica susceptível a lixiviação por chuvas intensas, devido a baixa capacidade de adsorção de $\mathrm{P}$ dos solos arenosos (Rheinheimer et al., 2003).

Entre as gramíneas forrageiras tropicais, a espécie Panicum maximum Jacq., com destaque para o cultivar Mombaça, é uma das forrageiras mais importantes para a produção pecuária nas regiões tropicais e subtropicais do mundo (Herling et al., 2000) devido à seu elevado potencial de produção e valor nutritivo (Santos et al., 1999). Entretanto, quando não são observadas técnicas de manejo adequadas, essas pastagens se degradam rapidamente e dão lugar para espécies de hábito prostrado, geralmente menos exigentes e mais resistentes ao manejo inadequado, porém, de menor potencial de produção (Camargo-Bortolin et al. 2007).

A recomendação de adubação deve estar relacionada aos principais nutrientes, seguindo criteriosamente a análise de solo e a necessidade da espécie forrageira específica a ser cultivada (Patês et al., 2007). De maneira geral, os cultivares de Panicum maximum apresentam alta resposta à adubação com fósforo (Gheri et al., 2000), porém, é imprescindível o aprimoramento de técnicas para aumentar a utilização deste nutriente, sem, contudo, elevar os custos de produção (Franco, 2003).

Com base no exposto, o presente trabalho teve por objetivo avaliar as características agronômicas e o estado nutricional do capim Mombaça submetido a doses de fósforo e cultivado em solos com texturas arenosa e argilosa.

\section{MATERIAL E MÉTODOS}

O experimento foi conduzido entre dezembro de 2005 a maio de 2006 em ambiente protegido na Fazenda Experimental Marcello Mesquita Serva, da Universidade de Marília - UNIMAR, localizada no município de Marília-SP.

O delineamento experimental empregado foi o inteiramente casualizado em esquema fatorial $4 \times 2$, com cinco repetições, totalizando 40 unidades experimentais. Os tratamentos foram obtidos a partir da combinação de quatro doses de fósforo $(0$, 300,600 e $900 \mathrm{mg} \mathrm{P} \mathrm{kg}^{-1}$ de solo) com solos de duas texturas (arenoso e argiloso) (EMBRAPA, 2006).

O solo destinado para a composição da textura argilosa e arenosa foi coletado do horizonte superficial de solos classificados como Latossolo Vermelho Amarelo Eutrófico e Argissolo Vermelho Amarelo Eutrófico (EMBRAPA, 2006), respectivamente, ambos oriundos do Município de Parapuã-SP. 
Para ambos solos foram realizadas análises químicas para amostras de solo coletadas na profundidade de $0-20 \mathrm{~cm}$, cujas características obtidas para o solo argiloso foram: $\mathrm{pH} \mathrm{Cacl}_{2} 6,2 \mathrm{~mol}^{-1}$; matéria orgânica $11,0 \mathrm{~g} \mathrm{dm}^{3}$; P disponível 5,0 $\mathrm{mg} \mathrm{dm}^{-3}$ (Resina); Al trocável $0,0 \mathrm{mmol}_{\mathrm{c}} \mathrm{dm}^{-3}$; Ca trocável 16,0 mmol dm${ }^{-3} ; \mathrm{Mg}$ trocável 6,0 $\mathrm{mmol} \mathrm{dm}^{-3}$, K trocável $3,0 \mathrm{mmol}_{\mathrm{c}} \mathrm{dm}^{-3}, \mathrm{~T} \mathrm{mmolc} \mathrm{dm}^{-3} 34,0$ e V(\%) 71,0; e para o solo arenoso foram: $\mathrm{pH}$ $\mathrm{Cacl}_{2} 6,0 \mathrm{~mol}^{-1}$; matéria orgânica $9,0 \mathrm{~g} \mathrm{dm}^{3} ; \mathrm{P}$ disponível 3,0 $\mathrm{mg} \mathrm{dm}^{-3}$ (Resina); Al trocável $0,2 \mathrm{mmol} \mathrm{dm}^{-3}$; Ca trocável 18,0 $\mathrm{mmol} \mathrm{dm}^{-3}$;

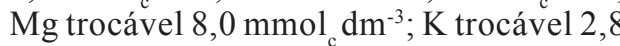
$\mathrm{mmol}_{\mathrm{c}} \mathrm{dm}^{-3}$; T 47,0 $\mathrm{mmol}_{\mathrm{c}} \mathrm{dm}^{-3} \mathrm{e} \mathrm{V}(\%) 63$.

As unidades experimentais foram representadas por vasos plásticos com capacidade para $5 \mathrm{dm}^{-3}$ de solo, enquanto como substrato para o crescimento das plantas foi utilizado os solos de textura arenosa e argilosa submetidos à secagem em ambiente sombreado e peneiramento realizados após a coleta.

Em função da elevada saturação por bases observada nas análises de solo não foi necessária a aplicação de calcário. As doses de $\mathrm{P}$ referentes à cada tratamento foram distribuídas e incorporadas manualmente ao volume de solo de cada unidade experimental, tendo como fonte de $\mathrm{P}$ o superfosfato triplo $\left(45 \%\right.$ de $\left.\mathrm{P}_{2} \mathrm{O}_{5}\right)$.

Por ocasião da semeadura da forrageira, foi realizada a adubação das unidades experimentais com reagentes P.A. nas dosagens de $150 ; 50 ; 100 ; 0,8 ; 4,0 ; 5,0 ; 0,15$; 3,6 e $1,5 \mathrm{mg} \mathrm{kg}^{-1}$ de solo para os nutrientes $\mathrm{K}, \mathrm{S}, \mathrm{N}, \mathrm{B}, \mathrm{Fe}, \mathrm{Zn}, \mathrm{Mo}, \mathrm{Mn}$ e $\mathrm{Cu}$, respectivamente, sendo utilizados como fontes o cloreto de potássio, sulfato de amônio, nitrato de amônio, ácido bórico, sulfato ferroso, sulfato de zinco, molibdato de sódio, sulfato de manganês e sulfato de cobre, respectivamente. Após a aplicação, os nutrientes foram incorporados manualmente ao volume de solo de cada vaso. Decorridos 15 dias da adubação foi realizada a semeadura manual da forrageira, com 15 sementes por vaso. Aos 15 dias após a emergência das plantas (DAE) realizou-se o desbaste, no qual permaneceram cinco plantas por vaso. Foram realizadas duas adubações em cobertura, aos 30 e 40 DAE, com a aplicação de $\mathrm{N}$ e K nas dosagens de 150 e $100 \mathrm{mg} \mathrm{kg}^{-1}$ de solo sob as formas de nitrato de amônio e cloreto de potássio, respectivamente para todos os tratamentos. Durante todo o experimento os vasos foram mantidos sob irrigação diária a fim de se manter a capacidade de campo.

Foram realizados dois cortes para as avaliações e coleta das amostras, sendo o primeiro realizado aos $70 \mathrm{DAE}$ e o segundo 60 dias após o primeiro. Na ocasião das avaliações foi determinado o número de perfilhos, obtido a partir da contagem manual de todos os perfilhos de cada vaso. Após a contagem dos perfilhos as plantas foram cortadas rente ao solo e foram separadas em lâminas foliares e colmos + bainhas, com posterior secagem em estufa com circulação forçada de ar, a $60-70^{\circ} \mathrm{C}$, por 72 horas para a determinação das produções de massa seca de folhas e de colmos.

Após o segundo corte, os vasos foram desmontados para a extração do sistema radicular das plantas, que foi lavado com água corrente em peneiras e submetido à secagem similarmente à parte aérea. Também por ocasião da desmontagem dos vasos foi realizada a coleta de amostras de solo para posterior determinação dos teores de $\mathrm{P}$.

As amostras da massa seca de folhas e de colmos foram moídas em moinho tipo Willey, com facas e câmara de inox e homogeneizadas para a formação de amostras da parte aérea, enquanto as amostras de solo foram submetidas à secagem à sombra. Ambas amostras de solo e tecido vegetal foram encaminhadas para o Laboratório de Análise de Solos e Tecido Vegetal da Faculdade de Ciências Agrárias da UNOESTE, Presidente Prudente-SP, para a determinação dos teores de P segundo a metodologia proposta por Nogueira e Souza(2005).

Os dados obtidos foram submetidos à 
Tabela I. Número de perfilhos do capim mombaça sob doses crescentes de $P$ no primeiro e segundo cortes em solo arenoso e argiloso. (Number of tillers of the mombaça grass under rates of $\mathrm{P}$ in the first and second cuts in sandy and loamy soil).

\begin{tabular}{lcccccccccc}
\hline $\mathrm{P}(\mathrm{mg} / \mathrm{kg})$ & 0 & 300 & $\begin{array}{c}\text { Corte } 1 \\
600\end{array}$ & 900 & Média & 0 & 300 & $\begin{array}{c}\text { Corte } 2 \\
600\end{array}$ & 900 & Média \\
\hline Arenoso & $18,51^{\mathrm{a}}$ & $57,35^{\mathrm{a}}$ & $\begin{array}{c}67,47^{\mathrm{a}} \\
\text { Argiloso }\end{array}$ & $62,00^{\mathrm{a}}$ & $51,33^{\mathrm{a}}$ & $16,29^{\mathrm{b}}$ & $55,38^{\mathrm{a}}$ & $71,55^{\mathrm{a}}$ & $55,93^{\mathrm{b}}$ & $49,79^{\mathrm{b}}$ \\
CV (\%) & $58,31^{\mathrm{a}}$ & $54,58^{\mathrm{b}}$ & $56,29^{\mathrm{b}}$ & $46,97^{\mathrm{b}}$ & $36,42^{\mathrm{a}}$ & $63,58^{\mathrm{a}}$ & $62,00^{\mathrm{a}}$ & $79,05^{\mathrm{a}}$ & $60,26^{\mathrm{a}}$ \\
\hline
\end{tabular}

abMédias seguidas da mesma letra minúscula na coluna não diferente estatisticamente pelo teste Tukey ao nível de $5 \%$ de probabilidade.

análise estatística, sendo que as doses de $\mathrm{P}$ foram comparadas por meio de análise de regressão e, para escolha do modelo, considerou-se significância de 5\% para os coeficientes das equações e os maiores valores para os coeficientes de determinação, enquanto os solos de diferentes texturas foram comparados através do teste Tukey ao nível de 5\% de significância.

\section{RESULTADOSEDISCUSSÃO}

Para o número de perfilhos (tabela I) houve efeito do tipo de solo, fósforo e da interação dos fatores em ambos cortes $(\mathrm{p}<0,01)$. Foi possível observar efeito

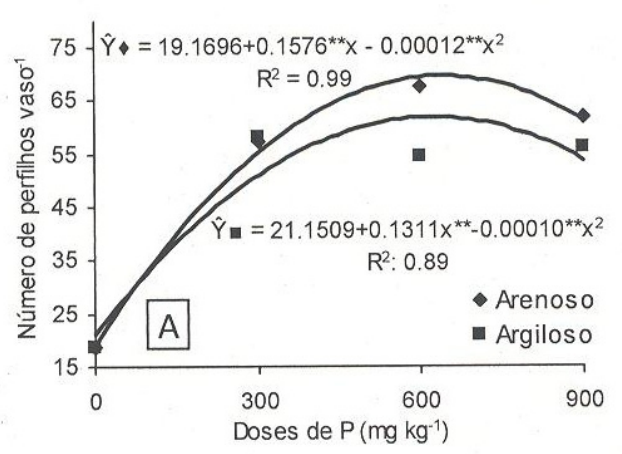

quadrático das doses de $\mathrm{P}$ sobre o número de perfilhos no primeiro corte, de forma que o máximo perfilhamento foi obtido com a dose estimada em $656,67 \mathrm{mg} \mathrm{P} \mathrm{dm}^{-3}$ para o solo arenoso e $655,50 \mathrm{mg} \mathrm{P} \mathrm{dm}^{-3}$ para o solo argiloso (figura 1). No segundo corte houve efeito quadrático no solo arenoso, com o máximo perfilhamento com a dose de 606,12 $\mathrm{mg} \mathrm{P} \mathrm{dm}{ }^{-3}$, enquanto para o solo argiloso foi observado efeito linear positivo (figura 1). Os resultados concordam com os obtidos por Mesquita et al. (2004), que ao trabalharem com doses crescentes de $\mathrm{P}$ em diferentes tipos de solo sobre os capins marandú, andropogon e mombaça também observaram para o perfilhamento ajuste ao modelo

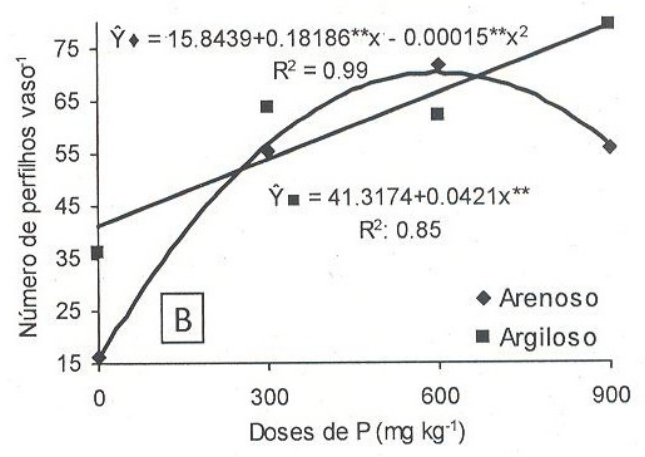

Figura 1. Número de perfilhos do capim mombaça sob doses crescentes de P no primeiro (A) e segundo $(B)$ cortes em solo arenoso e argiloso. ** significativo a $1 \%$ de probabilidade pelo teste $t$. (Number of tillers of mombaça grass under rates of $P$ in the first $(A)$ and second $(B)$ cuts in sandy and loamy soil. ${ }^{* *}$ significant to $1 \%$ of probability for the test $\mathrm{t}$ ).

Archivos de zootecnia vol. 61, núm. 235, p. 400. 
quadrático de regressão. Ferreira et al. (2008), trabalhando com doses de P em um Nitossolo também observaram resposta linear para o perfilhamento do capim mombaça. A superioridade do solo argiloso em relação ao arenoso no segundo corte pode estar relacionada com o fator capacidade desse solo, que lhe permite manter mais constante o teor de P na solução do solo (Novais et al., 2007). Dessa forma, apesar de possuir maior capacidade de adsorção, em função das altas doses aplicadas, o solo argiloso pode ter mantido um maior teor de P na solução do solo disponível para as plantas, pois segundo Boschetti et al. (1998), a capacidade dos solos em adsorver $\mathrm{P}$ influencia marcadamente a resposta das plantas à aplicação de fertilizantes e à calibração do $P$ disponível do solo.

No primeiro corte foi possível observar efeito significativo das doses de $\mathrm{P}(\mathrm{p}<0,01)$ e da interação dos fatores $(\mathrm{p}<0,05)$ sobre a produção de massa seca da parte aérea (PMP), porém, sem significância para solo $(\mathrm{p}<0,05)$. No desdobramento da interação, verificou-se que o PMP ajustou-se à função quadrática de regressão tanto no solo arenoso quanto no solo argiloso, sendo que os valores mínimos foram obtidos com as doses de $\mathrm{P}$ de 575,00 e 650,00 $\mathrm{mg} \mathrm{P} \mathrm{dm}^{-3}$, respectivamente. Para o segundo corte não houve efeito significativo dos fatores estudados, sendo que o PMP obtido foi de $0,83 \mathrm{~g}$. A ausência de significância entre tipos de solo e entre doses de $\mathrm{P}$ pode estar relacionada à baixa fertilidade natural destes dois tipos de solo e que quando submetidos à alguma aplicação de fertilização proporciona um melhor desenvolvimento da vegetação e uma melhor cobertura do solo, independente da textura avaliada (Sampaio etal., 2003).

A correlação negativa entre número e peso de perfilhos é explicada por Lemaire e Chapman (1996), os quais relataram que há redução no vigor e peso do perfilho com o aumento da população de perfilhos na planta, enquanto Luz et al. (2000), verificaram que o comportamento entre densidade e peso médio de perfilhos foi inversamente proporcional, sendo o peso mais determinante na produção de matéria seca que o número deles (figura 2). O trabalho de Sbrissia e Da Silva (2008) comprova o conceito proposto por Matthew et al. (1995) de que a correlação negativa entre número e peso de perfilhos é devida ao mecanismo de compensação tamanho/densidade populacional de perfilhos em comunidades de gramíneas, que proporciona maior densidade de perfilhos mais leves em pastagens.

A produção de MS de folhas não foi afetada pelos tipos de solo nos dois cortes avaliados $(p>0,05)$, porém foi influenciada significativamente nos dois cortes pelas doses de $P(p<0,01)$, e pela interação $(p<0,05)$. Tanto no primeiro como no segundo corte a produção de MS de folhas se ajustou ao modelo quadrático de regressão (figura 3). No primeiro corte as máximas produções foram obtidas com as doses de 806 e $618 \mathrm{mg}$ $\mathrm{P} \mathrm{dm^{-3 }}$ para os solos arenoso e argiloso, respectivamente. Já para o segundo corte, as máximas produções para os solos arenoso e argiloso foram obtidas com as doses de

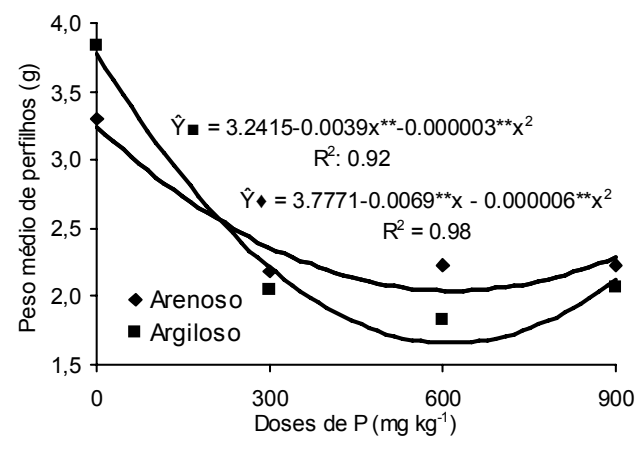

Figura 2. Peso médio de perfilhos do capim mombaça sob doses crescentes de P aos 60 dias após a emergência. **significativo a $1 \%$ de probabilidade pelo teste $t$. (Medium weigh of tillers of mombaça grass under rates of $\mathrm{P}$ to 60 after emergency ** significant to $1 \%$ of probability for the test $t$ ). 

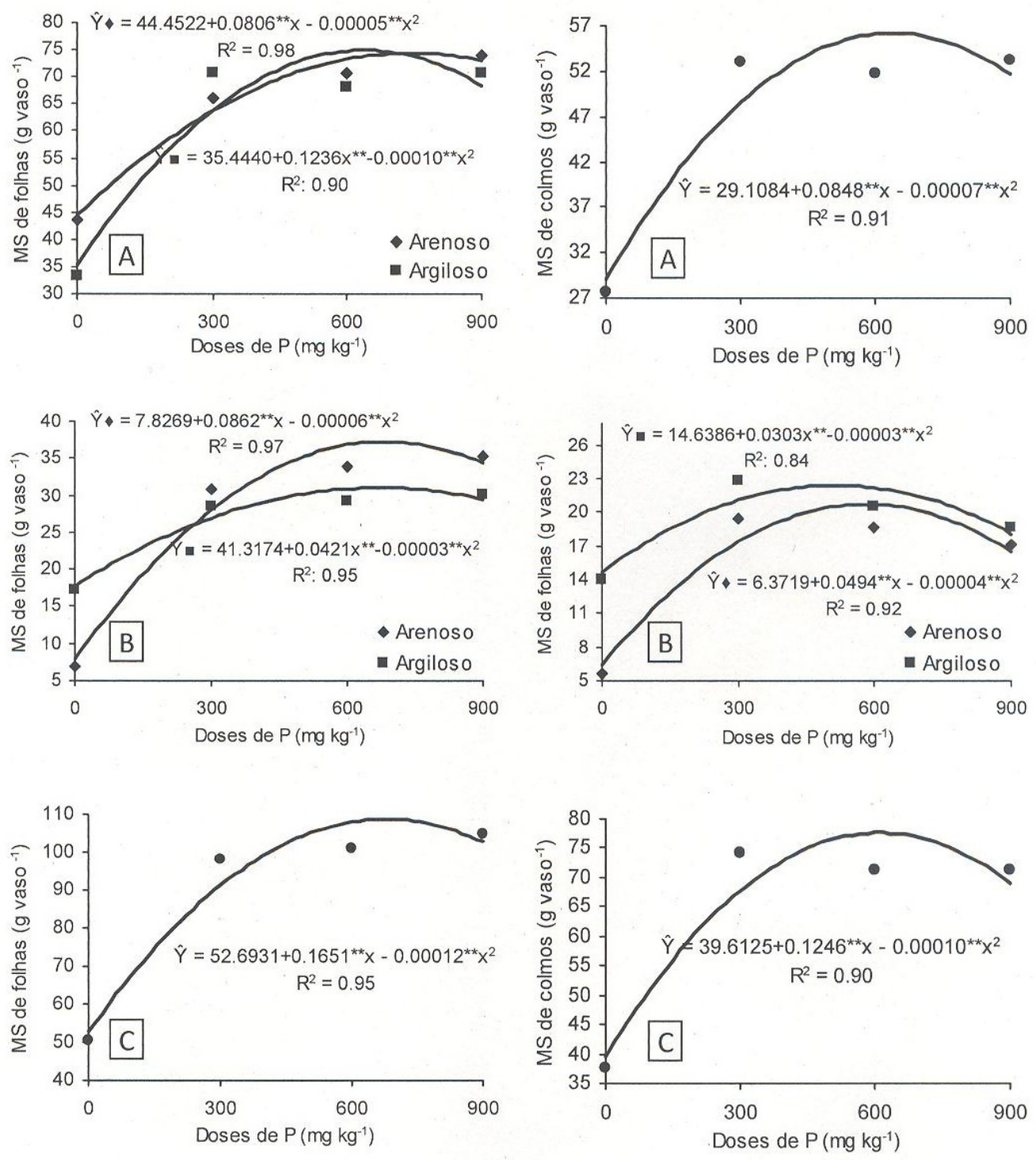

Figura 3. Produção de MS de folhas do capim mombaça sob doses crescentes de P no primeiro (A) e segundo (B) cortes, e na soma destes $(C)$ em solo arenoso e argiloso. ${ }^{*}$ *ignificativo a $1 \%$ de probabilidade pelo teste $t$. (Dry matter production of leaves of the mombaça grass under rates of $P$ in the first $(A)$ and second (B) cuts and in the sum of these (C) in sandy and loamy soils. ${ }^{* *}$ significant to $1 \%$ of probability for the test $\mathrm{t}$ ).

Figura 4. Produção de MS de colmos do capim mombaça sob doses crescentes de P no primeiro (A), segundo (B) e na soma dos dois cortes $(C)$ em solo arenoso e argiloso. **significativo a $1 \%$ de probabilidade pelo teste $t$. (Dry matter production of stems of mombaça grass under rates of $P$ in the first $(A)$, and second (B) cuts and in the sum of the two cuts (C) in sandy and loamy soils. ${ }^{* *}$ significant to $1 \%$ of probability for the test $\mathrm{t}$ ).

Archivos de zootecnia vol. 61, núm. 235, p. 402. 
718 e $702 \mathrm{mg} \mathrm{P} \mathrm{dm}^{-3}$, respectivamente. Esse resultado é semelhante ao obtido por Ferreira et al. (2008), que ao trabalharem com doses crescentes de $\mathrm{P}$ em capim mombaça, observaram resposta quadrática para a produção de MS de folhas com idade de rebrota de 35 dias. Melo et al. (2007), estudando doses crescentes de P combinadas com silício também observaram aumento na produção de MS de folhas com o aumento das doses de P. O aumento da produção de folhas era esperado, pois o fósforo é um elemento essencial ao crescimento e reprodução das plantas, as quais não alcançam seu máximo potencial produtivo sem um adequado suprimento nutricional (Marschner, 1995). O fósforo é componente de compostos importantes das células vegetais, incluindo fosfato presente nas moléculas de açúcares, intermediários da respiração e fotossíntese, bem como dos fosfolipídeos que compõem as membranas vegetais (Taiz e Zeiger, 2004).

Para a produção final (soma dos dois cortes) de massa de folhas houve efeito significativo apenas das doses de $\mathrm{P}(\mathrm{p}<0,05)$, com ajuste ao modelo quadrático de regressão. A máxima produção de massa de folhas $(109,48 \mathrm{~g})$ foi obtida com a dose de $688 \mathrm{mg} \mathrm{P} \mathrm{dm}^{-3}$, representando um aumento de $46 \%$ na produção.

No estudo da produção de colmos, no primeiro corte verificou-se significância para os tipos de solo $(\mathrm{p}<0,01)$ e para as doses de
$\mathrm{P}(\mathrm{p}<0,01)$, sem efeito significativo para a interação $(p>0,05)$. O solo argiloso proporcionou maior produção de massa de colmos $(47,48 \mathrm{~g})$ em relação ao solo arenoso $(45,26$ g). As doses de $\mathrm{P}$ proporcionaram ajuste ao modelo quadrático de regressão (figura 4), com a máxima produção de massa de colmo na dose de $606 \mathrm{mg} \mathrm{P} \mathrm{dm}^{-3}$. No segundo corte foi observada significância para os tipos de solo, doses de $\mathrm{P}$ e interação $(\mathrm{p}<0,01)$. No desdobramento das doses de $\mathrm{P}$ nos tipos de solo, constatou-se ajuste ao modelo quadrático de regressão (figura 4), sendo que as máximas produções de massa de colmo foram obtidas com as doses de $617 \mathrm{e}$ $505 \mathrm{mg} \mathrm{P} \mathrm{dm}^{-3}$ para os solos arenoso e argiloso, respectivamente. Na avaliação da produção total de MS de colmos (soma dos dois cortes), houve efeito significativo dos tipos de solo $(\mathrm{p}<0,01)$ e das doses de $\mathrm{P}$ $(\mathrm{p}<0,01)$. O solo argiloso proporcionou produção de colmos superior ao solo arenoso (tabela II). Para as doses de P foi constatado ajuste ao modelo quadrático de regressão, e a máxima produção foi obtida com a dose de $623 \mathrm{mg} \mathrm{P} \mathrm{dm}^{-3}$. Para a produção de massa de colmos, constata-se que houve comportamento semelhante ao obtido para a produção de massa de folhas. Esse fato pode estar diretamente associado à produção de MS foliar, pois segundo Forni et al. (2000), o maior desenvolvimento dos colmos resulta da necessidade de sustentação das maiores produções de lâminas foliares.

Tabela II. Produção de MS de colmos (g/por vaso) do capim mombaça sob doses crescentes de $P$. (Dry matter production of stems (g/jar) of the mombaça grass under rates of $\mathrm{P}$ ).

\begin{tabular}{|c|c|c|c|c|c|c|c|c|c|c|c|}
\hline \multirow[b]{2}{*}{$P(\mathrm{mg} / \mathrm{kg})$} & \multicolumn{5}{|c|}{ Corte 1} & \multicolumn{5}{|c|}{ Corte 2} & \multirow{2}{*}{$\begin{array}{c}\text { Final } \\
\text { Média }\end{array}$} \\
\hline & 0 & 300 & 600 & 900 & Média & 0 & 300 & 600 & 900 & Média & \\
\hline Arenoso & $26,55^{\mathrm{a}}$ & $51,70^{\mathrm{a}}$ & $51,12^{\mathrm{a}}$ & $51,67^{b}$ & $45,26^{b}$ & $5,68^{b}$ & $19,45^{b}$ & $18,68^{a}$ & $17,17^{\mathrm{a}}$ & $15,24^{b}$ & $60,50^{b}$ \\
\hline Argiloso & $28,72^{\mathrm{a}}$ & $54,26^{a}$ & $52,25^{a}$ & $54,68^{a}$ & $47,48^{a}$ & $14,07^{\mathrm{a}}$ & $22,81^{a}$ & $20,53^{a}$ & $18,69^{a}$ & $19,03^{a}$ & $66,50^{\mathrm{a}}$ \\
\hline CV (\%) & & & 4,89 & & & & & 14,99 & & & 6,30 \\
\hline
\end{tabular}

abMédias seguidas da mesma letra minúscula na coluna não diferente estatisticamente pelo teste Tukey ao nível de $5 \%$ de probabilidade. 


\section{OLIVEIRA, DEMINICIS, CASTAGNARAE GOMES}
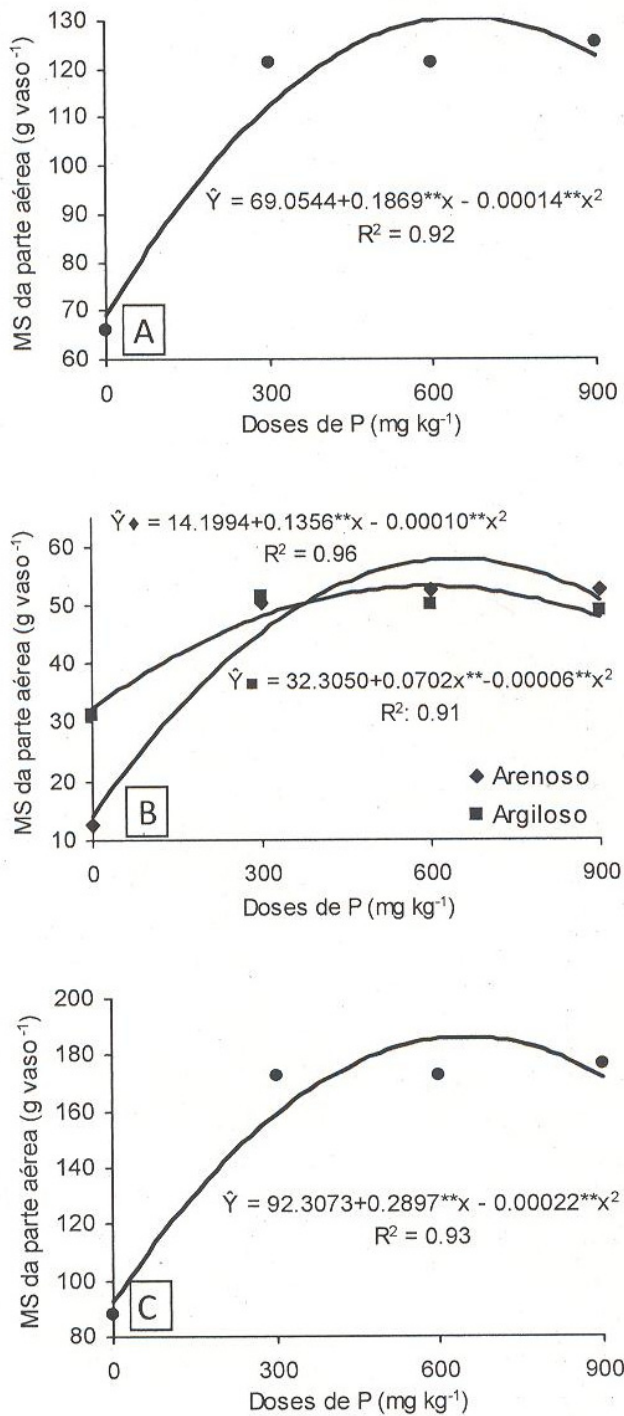

Figura 5. Produção de MS da parte aérea do capim mombaça sob doses crescentes de P no primeiro (A) e segundo cortes (B), e na soma dos mesmos (C) em solo arenoso e argiloso. ** significativo a $1 \%$ de probabilidade pelo teste $t$. (Dry matter production of the aerial part of the mombaça grass under rates of $P$ in the first $(A)$ and second (B) cuts, and in the sum of the two cuts (C) in sandy and loamy soils. ${ }^{* *}$ significant to $1 \%$ of probability for the test $\mathrm{t}$ ).
Tabela III. Produção de MS do sistema radicular (g/por vaso) do capim mombaça sob doses crescentes de P em solo arenoso e argiloso. (Roots dry matter production (g/jar) of the mombaça grass under $P$ fertilization in sandy and loamy soils).

\begin{tabular}{lcrrrr}
\hline $\mathrm{P}(\mathrm{mg} / \mathrm{kg})$ & 0 & 300 & 600 & 900 & Média \\
\hline Arenoso & $29,26^{\mathrm{a}}$ & $52,11^{\mathrm{a}}$ & $56,89^{\mathrm{a}}$ & $57,23^{\mathrm{a}}$ & $48,87^{\mathrm{a}}$ \\
Argiloso & $30,19^{\mathrm{a}}$ & $47,68^{\mathrm{b}}$ & $46,52^{\mathrm{b}}$ & $46,31^{\mathrm{b}}$ & $42,67^{\mathrm{b}}$ \\
CV (\%) & & & 6,27 & &
\end{tabular}

abMédias seguidas da mesma letra minúscula na coluna não diferente estatisticamente pelo teste Tukey ao nível de $5 \%$ de probabilidade.

$\mathrm{Na}$ análise das produções de MS de folhas e de colmos somadas, para o primeiro corte foi observado efeito significativo apenas das doses de $\mathrm{P}(\mathrm{p}<0,01)$, enquanto para o segundo corte foi observado efeito significativo dos tipos de solo, das doses de $\mathrm{P} \mathrm{e}$ da interação dos fatores $(p<0,01)$. No primeiro corte a produção de MS da parte aérea se ajustou ao modelo quadrático de regressão (figura 5-A), com a máxima produção na dose de $667 \mathrm{mg} \mathrm{P} \mathrm{dm}^{-3}$. Para o

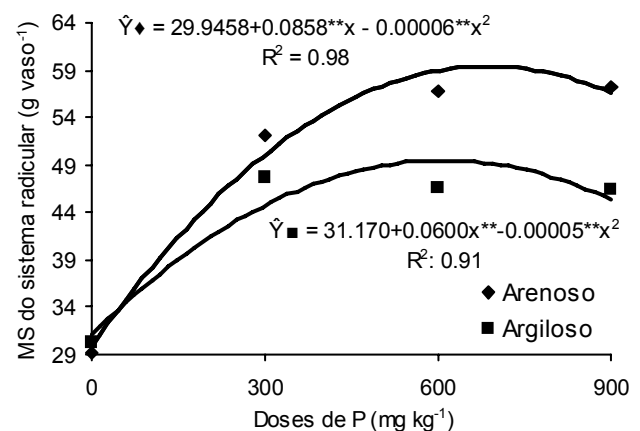

Figura 6. Produção de MS do sistema radicular do capim mombaça sob doses crescentes de P em solo arenoso e argiloso. **significativo a $1 \%$ de probabilidade pelo teste $t$. (Roots dry matter production in mombaça grass under $P$ fertilization in sandy and loamy soils. ${ }^{* *}$ significant to $1 \%$ of probability for the test $\mathrm{t}$ ).

Archivos de zootecnia vol. 61, núm. 235, p. 404. 


\section{ADUBAÇÃO COM P DO CAPIM MOMBAÇA EM SOLOS ARENOSOS E ARGILOSOS}

segundo corte, também foi observado ajuste ao modelo quadrático de regressão (figura 5-B), com as máximas produções nas doses de 678 e $585 \mathrm{mg} \mathrm{P} \mathrm{dm}^{-3}$ para os solos arenoso e argiloso, respectivamente. $\mathrm{Na}$ análise dos dois cortes somados houve efeito significativo apenas para as doses de $\mathrm{P}(\mathrm{p}<0,05)$, com ajuste ao modelo quadrático de regressão (figura 5-C), de forma que a máxima produção de MS foi obtida com a dose de $658 \mathrm{mg} \mathrm{P} \mathrm{dm}^{-3}$.

Para o sistema radicular foi observada significância para a produção de MS dos tipos de solo $(\mathrm{p}<0,01)$, das doses de $\mathrm{P}$

\section{BIBLIOGRAFIA}

Belarmino, M.C.J., Pinto, J.C., Rocha, G.P., Neto, A.E.F. e De Morais, A.R. 2003. Altura de perfilho e rendimento de matéria seca de capim Tanzânia em função de diferentes doses de superfosfato simples e sulfato de amônio. Ciên Agrotecnol, 27: 879-885.

Boschetti, A.N.G., Quintero, G.C.E. e Benavidez, Q.R.A. 1998. Caracterização do fator capacidade de fósforo em solos de Entre Ríos, Argentina. Argentina. Rev Bras Ciên Solo, 22: 95-99.

Camargo-Bortolin, L.H.G., Santos, P.M. e Prado, C.H.B.A. 2007. Estratégia de sobrevivência de Panicum maximum Tanzânia sob pastejo rotacionado. Arch Zootec, 56: 169-180.

Cecato, U., Pereira, L.A.F. e Jobim, C.C. 2004. Influência das adubações nitrogenada e fosfatada sobre a composição químicobromatológica do capim Marandu (Brachiaria brizantha (Hochst) Stapf cv. Marandu). Acta Scient, 26: 409-416.

Cecato, U., Skrobot, V.D., Fakir, G.M., Jobim, C.C., Branco, A.F., Galbeiro, S. e Janeiro, V. 2007 Características morfogênicas do capimmombaça (Panicum maximum Jacq. cv. Mombaça) adubado com fontes de fósforo, sob pastejo. Rev Bras Zootecn, 36: 1699-1706.

EMBRAPA. 2006. Empresa Brasileira de Pesquisa Agropecuária. Embrapa Centro Nacional de Pesquisa de Solos. Sistema brasileiro de classificação de solos. $2^{a}$ ed. Rio de Janeiro. $306 \mathrm{pp}$.

Ferreira, E.M., Santos, A.C., Araújo, L.C. e Cunha,
( $p<0,01)$ e da interação dos fatores $(p<0,01)$. No desdobramento das doses de $P$ para cada tipo de solo foi possível verificar ajuste da produção de MS do sistema radicular ao modelo quadrático de regressão, com as máximas produções de MS de raízes nas doses de 715 e $600 \mathrm{mg} \mathrm{P} \mathrm{dm}^{-3}$, para os solos arenoso e argiloso respectivamente. $\mathrm{Na}$ análise do desdobramento dos tipos de solo em cada dose de $\mathrm{P}$ estudada, verificou-se que a partir da dose de $300 \mathrm{mg} \mathrm{P} \mathrm{dm}^{-3}$ o solo arenoso proporcionou maior desenvolvimento do sistema radicular em relação ao solo argiloso (tabela III e figura 6).

O.F.R. 2008. Características agronômicas do Panicum maximum cv. Mombaça submetido a níveis crescentes de fósforo. Ciên Rural, 38 484-491.

Fonseca, D.M., Gomide, J.A. e Alvarez, V.H. 2000 Absorção, utilização e níveis críticos internos de fósforo e perfilhamento em Adropogon gayanus e Panicum maximum. Rev Bras Zootecn, 29: 1918-1929.

Forni, S., Michel Filho, L. e Favoretto, V. 2000. Efeito de diferentes doses de adubação com NPK sobre a produção, qualidade e estrutura das cultivares Tanzânia e Mombaça de Panicum maximum Jacq. Reunião Anual da Sociedade Brasileira de Zootecnia/Gnosis, 37. Anais... Viçosa, MG. CD-ROM. Forragicultura. Apresentação oral. FOR-702.

Franco, H.C.J. 2003. Avaliação agronômica de fontes e doses de fósforo para o capim Tifton 85. Dissertação (Mestrado em Agronomia). Universidade Estadual Paulista. Jaboticabal. 80 pp.

Gheri, E.O., Cruz, M.C.P. e Ferreira, M.E. 2000. Nível crítico de fósforo no solo para Panicum maximum Jacq. cv. Tanzânia. Pesqui Agropecu Bras, 35: 1809-1816.

Herling, V.R., Braga, G.J., Luz, P.H.C. e Otani, L. 2000. Tobiatã, Tazânia e Mombaça. Simposio sobre Manejo da Pastagem, 17. Anais... FEALQ. Piracicaba. pp. 21-64.

Lemaire, E. and Chapman, D. 1996. Tissue flows in grazed plant comunities. In: Hodgson, I., A.W. 


\section{OLIVEIRA, DEMINICIS, CASTAGNARA E GOMES}

Illius (Eds.). The ecology and management of grazing systems. CAB International. UK. pp. 336.

Luz, P.H.C, Herling, V.R. e Braga, G.J. 2000. Efeitos de tipos, doses e incorporação de calcário sobre características agronômicas e fisiológicas do capim-Tobiatã (Panicum maximum Jacq.). Rev Bras Zootecn, 29: 964-970.

Marschner, H. 1995. Mineral nutrition of higher plants. $2^{\mathrm{a}}$ ed. Academic. London. 889 pp.

Matthew, C., Lemaire, G., Sackville Hamilton, N.R. and Hernandez-Garay, A. 1995. A modified self-thinning equation does describe size/ density relationships for defoliated swards. Ann Bot, 76: 579-587.

Melo, S.P., Monteiro, F.A. and Manfredin, D. 2007. Silicate and phosphate combinations for marandu palisadegrass growing on an oxisol. Sci Agric, 64: 275-281.

Mesquita, E.E., Pinto, J.C., Furtini Neto, A.E., Santos, I.P.A. e Tavares, V.B. 2004. Teores críticos de fósforo em três solos para o estabelecimento de capim-Mombaça, capim-Marandu e capimAndropogon em vasos. Rev Bras Zootecn, 33: 290-301.

Nogueira, A.R.A. e Souza, G.B. 2005. Manual de laboratórios: Solo, água, nutrição vegetal, nutrição animal e alimentos. Embrapa Pecuária Sudeste. São Carlos. 313 pp.

Novais, R.F., Alvarez, V.H., Barros, N.F., Fontes, R.L.F., Cantarutti, R.B. e Neves, J.C. 2007 Fertilidade do solo. Sociedade Brasileira de Ciência do Solo. Viçosa. 1017 pp.

Oliveira, V.A., Borges, L.C., Calil, P.M., Almeida, L.L.C., Azevedo, W.R., Nogueira, S.A.J. e Silva, M.T.G. 2003. Diagnóstico agroambiental do entorno do Parque Nacional das Emas: $1^{\text {a }}$ Fase. $2^{a}$ ed. Agência Goiana de Desenvolvimento Rural e Fundiário - Agenciarural. Goiânia. Vol.
500. $227 \mathrm{pp}$.

Patês, N.M.S., Pires, A.J.V., Silva, C.C.F., Santos, L.C., Carvalho, G.G.P. e Freire, M.A.L. 2007. Características morfogênicas e estruturais do capim-tanzânia submetido a doses de fósforo e nitrogênio. Rev Bras Zootecn, 36: 1736-1741.

Rheinheimer, D.S., Anghinoni, I., Conte, E., Kaminski, J. e Gatiboni, L.C. 2003. Dessorção de fósforo avaliada por extrações sucessivas em amostras de solo provenientes dos sistemas plantio direto e convencional. Ciên Rural, 33: 1053-1059.

Sampaio, F.A.R., Fontes, L.E.F., Costa, L.M e Jucksch. I. 2003. Balanço de nutrientes e da fitomassa em um Argissolo Amarelo sob floresta tropical amazônica após a queima e cultivo com arroz. Rev Bras Ciên Solo, 27: 1161-1170.

Santos, I.P.A., Pinto, J.C., Siqueira, J.O., Morais, A.R. e Santos, C.L. 2002. Influência do fósforo, micorriza e nitrogênio no conteúdo de minerais de Brachiaria brizantha e Arachis pintoi consorciados. Rev Bras Zootecn, 31: 605-616. Santos, P.M., Corsi, M. e Balsalobre, M.A.A. 1999. Efeito da freqüência de pastejo e da época do ano sobre a produção e a qualidade em Panicum maximum cvs. Tanzânia e Mombaça. Rev Bras Zootecn, 28: 244-249.

Sbrissia, A.F. e Da Silva, S.C. 2008. Compensação tamanho/densidade populacional de perfilhos em pastos de capim-marandu. Rev Bras Zootecn, 37: 35-47.

Taiz, L. e Zeiger, E. 2004. Fisiologia vegetal. Artmed. Porto Alegre. pp. 449-484.

Vitor, C.M.T., Fonseca, D.M., Cóser, A.C., Martins, C.E., Nascimento Júnior, D. e Ribeiro Júnior, J.I. 2009. Produção de matéria seca e valor nutritivo de pastagem de capim-elefante sob irrigação e adubação nitrogenada. Rev Bras Zootecn, 38: 435-442.

Archivos de zootecnia vol. 61, núm. 235, p. 406. 